\title{
Aging Reduces the Expression of Lung CINC and MCP-1 mRNA in a $P$. aeruginosa Rat Model of Infection
}

\author{
Jie Wen, ${ }^{1}$ Cheng-Mei Li, ${ }^{2}$ Li Gu, ${ }^{2}$ Shao-jun Yin, ${ }^{3,5}$ Wei Li, ${ }^{4}$ and Rong Yang ${ }^{2}$
}

\begin{abstract}
We investigated dynamic changes of inflammatory cell infiltration and expression of cytokine-induced neutrophil chemoattractant (CINC) and monocyte chemoattractant protein-1 (MCP-1) mRNA in aged rats with Pseudomonas aeruginosa pulmonary infection. Disease manifestation and 1ung tissue pathology (lesion dispersion, inflammatory reactions, tissue edema and bleeding) were more severe in aged rats than young rats. At various time points, lung tissue polymorphonuclear neutrophil and mononuclear macrophage numbers were lower in the aged group than the young group $(P<0.05)$, and at $24 \mathrm{~h}$ there was no difference in mononuclear macrophage numbers. After inoculation with $P$. aeruginosa, CINC and MCP-1 mRNA expression increased in both groups, but the peak lagged in old rats compared with young. Thus, aging can reduce the expression of CINC and MCP-1 mRNA in lung tissues, and reduce the infiltration of neutrophils and monocyte-macrophages induced by CINC and MCP-1. This might lead to increased risk of pneumonia in elderly patients.
\end{abstract}

KEY WORDS: chemokines; elderly; lung infection; CINC mRNA; MCP-1 mRNA.

\section{INTRODUCTION}

Leukocyte migration from the blood into tissues in the context of inflammation is a complex phenomenon representing the integration of chemoattraction. Chemokines are a family of polypeptides with four conserved cysteine residues that form two disulfide bonds. The family can thus be subdivided into two large groups, depending on whether there is an intervening amino acid between the first two cysteines yield in the CXC and CC subgroups, respectively [1-3].

J. Wen, C.-M. Li and L. Gu contributed equally to this work and should be regarded as co-first authors.

\footnotetext{
${ }^{1}$ Department of Respiratory Medicine, Traditional Chinese Medical of Xinjiang Uygur Autonomous Region, Xinjiang 830000, China

${ }^{2}$ Department of Paediatrics, Tenth People's Hospital, Tongji University, Shanghai, China

${ }^{3}$ Department of Respiratory Medicine Shanghai 6th People's East Hospital, Jiaotong University School of Medicine, Pudong Nanhui New City, West Three Lake Road No. 222, Shanghai, China

${ }^{4}$ Department of Geriatric Medicine, Tenth People's Hospital, Tongji University, Shanghai, China

${ }^{5}$ To whom correspondence should be addressed at Department of Respiratory Medicine Shanghai 6th People's East Hospital, Jiaotong University School of Medicine, Pudong Nanhui New City, West Three Lake Road No. 222, Shanghai, China. E-mail: yinshaojun2010@126.com
}

Generally, members of the CXC chemokines are chemotactic for neutrophils and $\mathrm{CC}$ chemokines are chemotactic for monocytes and a small subset of lymphocytes. Cytokine-induced neutrophil chemoattractants (CINC) are particular members of the CXC family that are active as neutrophil chemoattractants in vitro and in vivo. Monocyte chemoattractant protein-1 (MCP-1) is the major lymphocyte chemoattractant secreted by mitogen-stimulated peripheral blood mononuclear cells and acts as a potent T-lymphocyte and monocyte chemoattractant.

In recent years, with increasing socio-demographic aging, the number of aging infected patients has quickly increased, becoming a global problem [4]. The lung is frequently a site of infection in elderly patients. Studies have shown that altered cytokine systems due to aging can affect the pathophysiology of elderly pneumonia, but whether cytokines in the lung are also affected by aging is not clear. In this study, we used bacteriology, pathology and molecular biology to investigate the dynamic changes of inflammatory cell infiltration and the expression of CINC mRNA and MCP-1 mRNA in aged rats with Pseudomonas aeruginosa pulmonary infection. This might help us understand the possible mechanisms of cell penetration kinetics of lung inflammation, and help establish a basis for finding new treatment targets for aging pneumonia. 


\section{MATERIALS AND METHODS}

\section{Animals}

Sixty-eight male Sprague-Dawley rats were divided into two groups: old group and young group. Rats in the old group $(n=34)$, which were purchased from Beijing Vital River Laboratories, were 20-22 months old and weighed 700-900 g. The young group $(n=34)$ consisted of rats that were purchased from the Experimental Animal Center of Fudan University, were 5-6 months old, and weighed 460-580 g. All animals had unified numbering and were housed under specific pathogen-free conditions. Animals were maintained and used in accordance with the animal use regulations A-75-10-01.

\section{Pseudomonas aeruginosa}

$P$. aeruginosa standard strain (ATCC27853) was purchased from Zhongshan Hospital, Fudan Experimental Center of Clinical Microbiology, and was grown $35^{\circ} \mathrm{C}$ $\mathrm{MH}$ agar plate for $24 \mathrm{~h}$, then Maxwell tube and spectrophotometer colorimetry (wavelength $550 \mathrm{~nm}$, absorbance $0.5)$ was performed using a two Maxwell unit concentration $\left(6 \times 10^{8} \mathrm{cfu} / \mathrm{ml}\right)$ with sterile distilled water (most $P$. aeruginosa-induced pneumonia models used this concentration of bacteria $[5,6])$.

\section{Drugs and Reagents}

A solution of $0.9 \%$ sodium chloride (Shanghai Changzheng Fumin Jinshan Pharmaceutical Co., Ltd., China) and $3 \%$ pentobarbital sodium solution (Shanghai Xitang Biotechnology Co., Ltd., China) were used. Other reagents used were as follows: Anerdian (Shanghai Li Kang Hi-Tech Co., Ltd. China), 10 \% buffered formalin (Shanghai Tenth People's Hospital Central Laboratory, China), MH agar plates (Shanghai Reagent Supply Research Center products, China), Xylene (Shanghai Reagent Supply Research Center products, China), diethylpyrocarbonate (DEPC; Shanghai Biological Engineering Technology Company, China), DEPC-treated water (Shanghai SBS Genetech, Inc., China), Trizol RNA extraction kit (Invitrogen Corporation, USA), SYBRGreen PCR kit (Shanghai Dawei Biotechnology Company, China), PCR Primers (Shanghai Runna Biotechnology Co., Ltd. China), chloroform (HPLC grade; Shanghai Reagent Factory, China), isopropanol (HPLC grade; Chemical Plant in Suzhou Zhenya, China), and ethanol (AR grade, Shanghai Zhenxing Chemical Plant, China).

\section{Disease Modeling}

All experimental animals were divided into an aged group (experimental group) and young group (control group). Each group consisted of 24 rats and was divided into six subgroups at random: 0 (before inoculation), 2, 6, 9, 12 and $24 \mathrm{~h}$. Every sub-group contained four rats. Then the animal model was established by tracheal inoculation with $P$. aeruginosa and specimens were collected. Other rats $(n=20)$ were used to observe the survival rate after tracheal inoculation with $P$. aeruginosa. A solution of $3 \%$ sodium pentobarbital $(30 \mathrm{mg} / \mathrm{kg}$ ) was used to induce intraperitoneal anesthesia, and then a tracheotomy was performed to inoculate rats with bacteria $\left(0.2 \mathrm{ml}\right.$ ATCC27835, $\left.6 \times 10^{8} \mathrm{cfu} / \mathrm{ml}\right)$ to induce $P$. aeruginosa lung infection.

\section{Sample Collection}

Rats were euthanized at $0 \mathrm{~h}$ (before inoculation) or at 2, 6, 9, 12 and $24 \mathrm{~h}$ after inoculation and specimens were taken. At the corresponding time points, we used $3 \%$ sodium pentobarbital $(30 \mathrm{mg} / \mathrm{kg})$ for intraperitoneal anesthesia, and performed thoracotomy under sterile conditions to obtain heart blood and left lung bronchoalveolar lavage fluid. Then we measured whole blood leukocyte and alveolar lavage fluid leukocyte counts. Part of the right lung lower lobe was used for bacteriology, to determine the colony counts. The middle part right lung heart leaf was placed in $10 \%$ formalin, fixed and used for histology. The remaining lung tissue was frozen and kept at $-80{ }^{\circ} \mathrm{C}$ for chemokine gene expression by real-time PCR.

\section{Etiological Diagnosis}

Approximately $5 \times 5 \times 5 \mathrm{~mm}$ lung tissue was placed into a grinder to obtain lung tissue homogenates, which were then placed in blood agar at $37{ }^{\circ} \mathrm{C}$ for $24 \mathrm{~h}$. The successful establishment of the pneumonia model depends on the bacteriological index (lung homogenates colony counts) and histopathological examination. Modeling standards used previous definitions [7] as follows: the acute phase, (1) lung tissue bacterial content $>10^{5} \mathrm{cfu} / \mathrm{g}$, (2) histological examination, pathological changes include: pulmonary edema, fiber protein exudation, neutrophil infiltration; chronic phase: (1) lung tissue bacterial content $>10^{3} \mathrm{cfu} / \mathrm{g}$, (2) histological examination, pathological changes in the consolidation, including lung tissue, fibrosis, lymphocytic infiltration. Model standards were also defined according to Song and Model ZJ as previously described [8, 9]. The inflammatory cell infiltration from observed lesions mainly contained polymorphonuclear (PMN) leukocytes responding 
to acute inflammation, and mononuclear cells accompanied by lymphocytes, red blood cells and granulomatous responses induced by chronic inflammation.

\section{Whole Blood Leukocyte Count}

Whole blood leukocyte counts were performed using the CELL DYN3700 automatic blood cell analyzer detection mode of mammals [8].

\section{Pulmonary Histopathological Examination}

The right lung heart leaf was placed in $10 \%$ formalin to be fixed, then embedded in paraffin and sectioned $6 \mu \mathrm{m}$ for hematoxylin and eosin (HE) staining. The slices were observed by microscope, and PMN and monocytes/macrophages were counted by optical microscope count under 400 -fold magnification (field of view equivalent to $20,000 \mu^{2}$ ). Ten areas from each section were assessed double-blind. Results were expressed as the number of cells per unit area.

\section{Expression of CINC and MCP-1 by RT-PCR}

\section{Extraction of Total RNA}

RNA was obtained by Trizol extraction, and agarose gel electrophoresis was used for quality testing.

\section{cDNA Reverse Transcriptase}

Diluted RNA samples were used for reverse transcription. The reaction system included: $5 \times$ reverse transcriptase buffer $4 \mu \mathrm{l}$, oligo(dT) $0.5 \mu \mathrm{l}$; dNTPs, $0.5 \mu \mathrm{l}$; reverse transcriptase MMLV $1 \mu \mathrm{l}$; DEPC-treated water $10 \mu \mathrm{l}$; and RNA Template $4 \mu \mathrm{l}$. The total volume was $20 \mu \mathrm{l}$. The reaction conditions were as follows: $37^{\circ} \mathrm{C}$ for $1 \mathrm{~h}$, then $95{ }^{\circ} \mathrm{C}$ for $5 \mathrm{~min}$ to inactivate MMLV.

\section{Real-Time PCR}

We used real-time PCR to detect gene transcription of CINC and MCP-1 mRNA from different groups. Primer sequences were as follows: GAPDH: (5' primer): 5'CTCTACCCACGGCAAGTTCAA-3', (3' primer): 5'GGATGACCTTGCCCACAGC-3', amplified product length 515 bp; CINC sequence: (5' primer): 5'AACAGAGCACCATGGTCT-3', (3' primer): 5'GACGCCATCGGTGCAATCTA-3', amplification product length $337 \mathrm{bp}$; MCP-1 sequence: (5' primer): 5'CTCTTCCTCCACCACTATGC-3', (3' primer): 5'CTCTGTCATACTGGTCACTTC-3', amplification product length $457 \mathrm{bp}$. Then the prepared cDNA was amplified
Table 1. Comparing the Nose Scratching (Symptom) of Rats Between Two Groups After Inoculation of $P$. aeruginosa

\begin{tabular}{lcl}
\hline Time point $(\mathrm{h})$ & $\begin{array}{l}\text { Young group } \\
\text { (number of nose } \\
\text { scratching/the } \\
\text { total number) }\end{array}$ & $\begin{array}{l}\text { Aged group } \\
\text { (number of nose } \\
\text { scratching/the } \\
\text { total number) }\end{array}$ \\
\hline 0 & $(0 / 10)$ & $(0 / 10)$ \\
1 & $(5 / 10)$ & $(5 / 10)$ \\
2 & $(10 / 10)$ & $(10 / 10)$ \\
6 & $(9 / 10)$ & $(10 / 10)$ \\
9 & $(7 / 10)$ & $(8 / 10)$ \\
12 & $(6 / 10)$ & $(6 / 8)$ \\
24 & $(1 / 10)$ & $(5 / 7)$ \\
48 & $(0 / 10)$ & $(0 / 6)$ \\
\hline
\end{tabular}

by PCR as follows: SYBRGreen Mix $32.5 \mu$; upstream primer F $0.5 \mu \mathrm{l}$; downstream primer $\mathrm{R} 0.5 \mu \mathrm{l}$; ddH2O $14.5 \mu \mathrm{l}$; cDNA Template $2 \mu \mathrm{l}$, for a total volume of $50 \mu \mathrm{l}$. The reaction mix was placed in an ABI-7500 (ABI, USA) PCR thermal cycler for amplification. The reaction cycle was as follows: (1) denaturation of the initial template: $30 \mathrm{~s}$ at $95{ }^{\circ} \mathrm{C}$, one cycle; (2) denaturation of the Template $5 \mathrm{~s}$ at $95{ }^{\circ} \mathrm{C}$, annealing for $31 \mathrm{~s}$ at $60{ }^{\circ} \mathrm{C} 40$ cycles; (3) melting: $15 \mathrm{~s}$ at $95^{\circ} \mathrm{C}$, then $1 \mathrm{~min}$ at $60^{\circ} \mathrm{C}, 15 \mathrm{~s}$ at $95^{\circ} \mathrm{C}$ (collected fluorescence between $60^{\circ} \mathrm{C}$ and $95^{\circ} \mathrm{C}$ ), then $15 \mathrm{~s}$ at $40^{\circ} \mathrm{C}$. The standard curve was obtained by logarithmic fitting the $\mathrm{CT}$ value. The following equation was used to calculate the amplification efficiency: $E=10(-1 /$ slope $)$. The housekeeper gene, GAPDH, was used as an internal control. The relative content of the sample gene $=2-\Delta \mathrm{CT} \times 100(\Delta \mathrm{CT}=$ test gene $\mathrm{CT}$ - housekeeper gene CT).

Table 2. Comparing Cough (Symptom) of Rats Between Two Groups After Inoculation of $P$. aeruginosa

\begin{tabular}{lll}
\hline Time point (h) & $\begin{array}{l}\text { Young group } \\
\text { (number of cough/ } \\
\text { the total number) }\end{array}$ & $\begin{array}{l}\text { Aged group } \\
\text { (number of cough/the } \\
\text { total number) }\end{array}$ \\
\hline 0 & $0 / 10$ & $0 / 10$ \\
1 & $3 / 10$ & $5 / 10$ \\
2 & $5 / 10$ & $10 / 10$ \\
6 & $10 / 10$ & $10 / 10$ \\
9 & $6 / 10$ & $8 / 10$ \\
12 & $3 / 10$ & $7 / 8$ \\
24 & $1 / 10$ & $5 / 7$ \\
48 & $0 / 10$ & $0 / 6$ \\
\hline
\end{tabular}




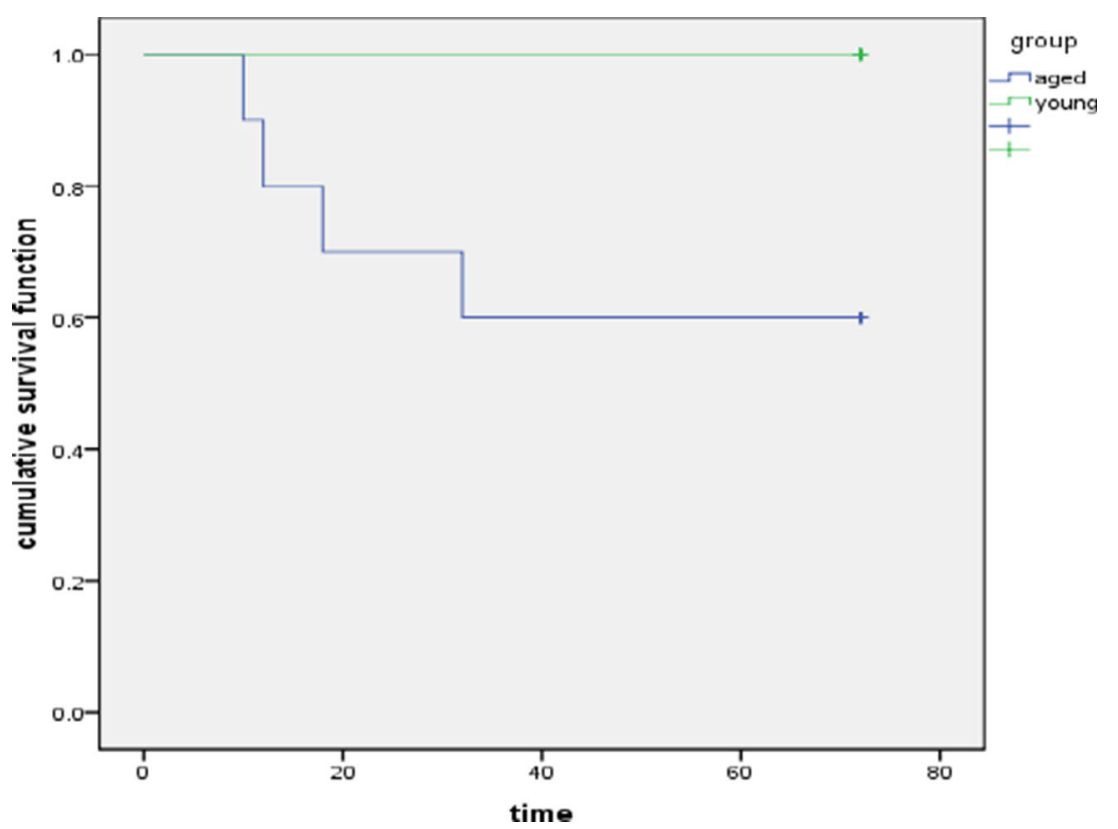

Fig. 1. Comparison of cumulative survival rates between two groups.

\section{Statistical Analysis}

Data are presented as mean \pm standard deviation (SD). Differences were considered statistically significant when $P<0.05$. Differences between groups of rats were determined by non-parametric tests.

\section{RESULTS}

\section{P. aeruginosa-Induced Pulmonary Infection}

One hour after inoculation with $P$. aeruginosa, there was no significant effect in either of the two groups, possibly due to the effect of the anesthetic.
At 2-4 h later, the young group showed brief breathing, frequent nose scratching and a cough that gradually increased in frequency. All these symptoms leveled off during 6-9 h after inoculation. At $9 \mathrm{~h}$, the young rats become more active and their respiratory rate began to reduce. At $24 \mathrm{~h}$, the young rats performed similarly to preoperative levels. At the time of $P$. aeruginosa inoculation, the aged rat group demonstrated shallow breathing, frequent scratching of the nose, and significant coughing. At $12-16 \mathrm{~h}$, all these symptoms had leveled off but were not restored until $24 \mathrm{~h}$ later. The aged rats appeared to move slowly and eat less compared with the young rat group (Tables 1 and 2).

Table 3. Dynamic Changes of Bacterial Load in Lung Tissue Before and After Inoculation of P. aeruginosa in Two Groups of Rats

\begin{tabular}{|c|c|c|c|c|}
\hline Time point (h) & $\begin{array}{l}\text { Young group } \\
\left(\times 10^{4} \mathrm{cfu} / \mathrm{ml} \text { mean } \pm \mathrm{SD}\right)\end{array}$ & $\begin{array}{l}\text { Aged group } \\
\left(\times 10^{4} \mathrm{cfu} / \mathrm{ml} \text { mean } \pm \mathrm{SD}\right)\end{array}$ & $t^{\mathrm{a}}$ & $P$ value \\
\hline 2 & $9.75 \pm 2.68$ & $23.95 \pm 3.93$ & -5.970 & 0.001 \\
\hline 6 & $10.95 \pm 2.12$ & $19.53 \pm 4.90$ & -3.337 & 0.034 \\
\hline 9 & $8.56 \pm 0.63$ & $13.10 \pm 1.69$ & -5.043 & 0.002 \\
\hline 12 & $7.31 \pm 1.11$ & $11.96 \pm 2.15$ & -3.870 & 0.008 \\
\hline 24 & $2.13 \pm 1.72$ & $5.82 \pm 2.27$ & -2.593 & 0.041 \\
\hline
\end{tabular}

Data presented as mean $\pm \mathrm{SD}$

${ }^{a}$ Non-parametric test 
Table 4. Dynamic Changes of White Blood Cells of Peripheral Blood Before and After Inoculation of P. aeruginosa in Two Groups of Rats

\begin{tabular}{lcccr}
\hline Time point $(\mathrm{h})$ & $\begin{array}{l}\text { Young group } \\
\left(\times 10^{9} / 1 \text { mean } \pm \mathrm{SD}\right)\end{array}$ & $\begin{array}{l}\text { Aged group } \\
\left(\times 10^{9} / 1 \text { mean } \pm \mathrm{SD}\right)\end{array}$ & $t^{\mathrm{a}}$ \\
\hline 0 & $3.63 \pm 0.38$ & $2.83 \pm 0.29$ & -3.337 & \\
2 & $6.63 \pm 1.28$ & $3.43 \pm 0.15$ & -3.593 & 0.015 \\
6 & $9.92 \pm 2.39$ & $4.65 \pm 2.56$ & -3.010 & 0.037 \\
9 & $13.33 \pm 2.32$ & $6.48 \pm 1.46$ & -5.012 & 0.024 \\
12 & $5.70 \pm 1.21$ & $9.20 \pm 1.36$ & -3.846 & 0.002 \\
24 & $9.73 \pm 2.36$ & $3.67 \pm 1.32$ & -4.663 & 0.009 \\
\hline
\end{tabular}

Data presented as mean $\pm \mathrm{SD}$

${ }^{a}$ Non-parametric test

\section{Survival}

Rats were observed for 7 days. All rats from the young group survived whereas four rats in the aged group died $(40 \%)$, one each at 10, 12, 18 and $32 \mathrm{~h}$ after inoculation. We use the Kaplan-Meier to describe the survival (Fig. 1).

\section{Bacteriological Counts of Lung Tissue}

After inoculation with $P$. aeruginosa, the bacterial load in lung tissue showed a downward trend in both groups. At $24 \mathrm{~h}$, it reached minimum levels. However, there was a slight increase at $6 \mathrm{~h}$ in the young group. At 2, 6, 9, 12 and $24 \mathrm{~h}$ after $P$. aeruginosa inoculation, the bacterial load in lung tissue from the older group was significantly higher than the young group $(P<0.001-0.041)$ (Table 3$)$.

\section{Peripheral Blood White Blood Cell Counts}

Before inoculation with $P$. aeruginosa, the total number of white blood cells in the peripheral blood of the old group was significantly lower than in the young group $(P<0.015)$. After inoculation with $\mathrm{P}$. aeruginosa, the total number of white blood cells in the peripheral blood of both groups increased and then decreased. The young group showed a peak at $9 \mathrm{~h}$, which then declined and increased again at $24 \mathrm{~h}$. The old group showed a peak at $12 \mathrm{~h}$ (the peak was lower than in the young group), which then declined slowly. At $24 \mathrm{~h}$, it was still approximately four times higher than the normal level. After inoculation with $P$. aeruginosa, the total number of white blood cells in the peripheral blood of the aged group was significantly higher than in the young group $(P<0.002-0.024)$ (Table 4).

\section{Pulmonary Histopathology}

Before inoculation with $P$. aeruginosa, lung histology was normal. After inoculation, the lung tissue from the two groups (the upper lobe and the lower lobe) showed varying degrees of edema, hemorrhage and fibrosis by gross examination. The young group showed significant changes between 6 and $12 \mathrm{~h}$ that disappeared by $24 \mathrm{~h}$. The aged group showed significant changes between 9 and 24 h. At 24 h, these changes were only slightly reduced compared with at the peak. By endoscopy, lesions in tissues of the young group were limited with inflammatory responses, relatively minor structural damage in lung tissues, and with a peak inflammatory response at 6-12 $\mathrm{h}$. In addition, there were large numbers of PMN and AM (alveolarmacrophage) aggregated in the lesions. In contrast, between 6 and $12 \mathrm{~h}$, lesions of the aged

Table 5. Dynamic Changes of PMN Infiltration into the Lung Tissue Before and After Inoculation of P. aeruginosa in Two Groups of Rats

\begin{tabular}{llll}
\hline Time point (h) & $\begin{array}{l}\text { Young group } \\
\left(20,000 \mu \mathrm{m}^{2} \text { mean } \pm \mathrm{SD}\right)\end{array}$ & $\begin{array}{l}\text { Aged group } \\
\left(20,000 \mu \mathrm{m}^{2} \text { mean } \pm \mathrm{SD}\right)\end{array}$ \\
\hline 0 & $6.75 \pm 0.96$ & $4.75 \pm 0.50$ & 0.168 \\
2 & $18.50 \pm 3.70$ & $9.75 \pm 2.50$ & 3.921 \\
6 & $28.25 \pm 2.99$ & $18.50 \pm 3.87$ & 3.987 \\
9 & $55.00 \pm 5.77$ & $27.75 \pm 3.77$ & 7.901 \\
12 & $53.75 \pm 4.79$ & $39.50 \pm 4.43$ & 4.0087 \\
24 & $32.75 \pm 3.30$ & $24.50 \pm 1.73$ & 0.007 \\
\hline
\end{tabular}

Data presented as mean $\pm \mathrm{SD}$

${ }^{a}$ Non-parametric test 
Table 6. Dynamic Changes of Monocyte/Macrophages Infiltration into the Lung Tissue Before and After Inoculation of P. aeruginosa in Two Groups of Rats

\begin{tabular}{|c|c|c|c|c|}
\hline Time point (h) & $\begin{array}{l}\text { Young group } \\
\left(20,000 \mu \mathrm{m}^{2} \text { mean } \pm \mathrm{SD}\right)\end{array}$ & $\begin{array}{l}\text { Aged group } \\
\left(20,000 \mu \mathrm{m}^{2} \text { mean } \pm \mathrm{SD}\right)\end{array}$ & $t^{\mathrm{a}}$ & $P$ value \\
\hline 0 & $5.75 \pm 1.50$ & $4.50 \pm 1.29$ & -1.263 & 0.250 \\
\hline 2 & $8.00 \pm 0.82$ & $6.75 \pm 0.50$ & 2.611 & 0.040 \\
\hline 6 & $10.50 \pm 1.91$ & $8.25 \pm 1.26$ & 1.964 & 0.097 \\
\hline 9 & $14.25 \pm 0.96$ & $10.00 \pm 0.82$ & 6.755 & 0.001 \\
\hline 12 & $20.75 \pm 1.71$ & $13.25 \pm 1.71$ & 6.221 & 0.001 \\
\hline 24 & $16.75 \pm 0.96$ & $15.25 \pm 1.71$ & 1.532 & 0.176 \\
\hline
\end{tabular}

Data presented as mean $\pm \mathrm{SD}$

${ }^{a}$ Non-parametric test

group lungs were diffuse with slight inflammatory response, although edema and hemorrhage were more common.

Measurement of leukocyte counts in lung tissues demonstrated that before inoculation, there were few aggregated PMN or monocytes/macrophages in the lungs of both groups, and although there were less in the aged group, this was not statistically significant $(P>0.05)$. After $P$. aeruginosa inoculation, the aggregation of PMN and monocytes/macrophages increased. The speed and magnitude of PMN in the young group was higher than in the aged group. The young group reached a peak at $9 \mathrm{~h}$ whereas the aged group reached a peak at $12 \mathrm{~h}$, then decreased gradually. For monocytes/macrophages, the young group reached a peak at $12 \mathrm{~h}$, and the aged group reached a peak at $24 \mathrm{~h}$. At each time point, the number of PMN in the lungs of the aged group were significantly lower than the young group $(P<0.001-0.010)$ (Table 5) and the number of monocytes/macrophages in the aged group were also lower than the young group. Differences at 2, 9 and $12 \mathrm{~h}$ were statistically significant $(P<0.001-0.040)$ (Table 6, Fig. 2).

\section{RT-PCR}

Before $P$. aeruginosa inoculation, low levels of CINC and MCP-1 mRNA were observed in rat lung tissue from the two groups. However, the transcription levels of MCP1 mRNA, but not CINC mRNA, were significantly higher in the aged group compared with the young group. With increasing time after inoculation, CINC and MCP-1 mRNA expression increased and was higher in the young group compared with the aged group. CINC mRNA levels reached a peak at $9 \mathrm{~h}$ in the young group, and at $12 \mathrm{~h}$ in the aged group, and then decreased. At 2, 6 and $9 \mathrm{~h}$ after inoculation with $P$. aeruginosa, CINC mRNA expression in the lungs of the aged group were significantly lower than in the young group $(P<0.002-0.026)$. MCP-1 mRNA levels in the young group reached a peak at $9 \mathrm{~h}$ and then declined, whereas in the aged group MCP-1 mRNA levels were downregulated at 2, 6 and $9 \mathrm{~h}$ after inoculation. The transcription levels of MCP-1 mRNA in the aged group were significantly lower than in the young group $(P<0.001-0.014)$ (Tables 7 and 8$)$.

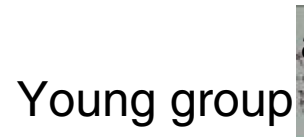

Aged group
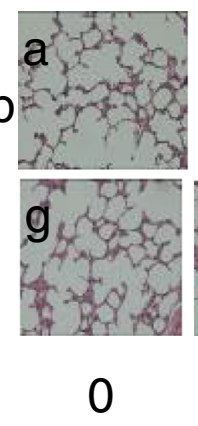
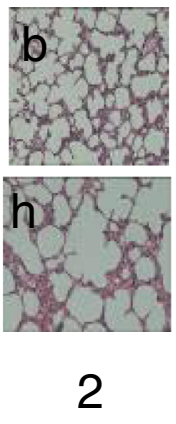

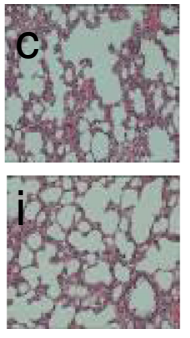

6

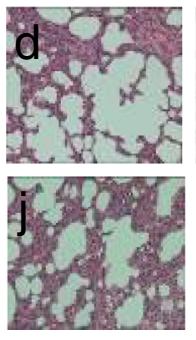

9

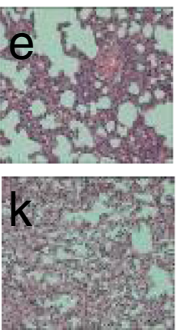

12

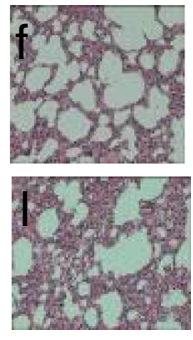

24

Time after inoculation (h)

Fig. 2. Histology of lung tissue at the indicated time points after inoculation of $P$. aeruginos $a$ in the young and aged group of rats. Magnification, $\times 400$. 
Table 7. Dynamic Changes of Lung Tissue CINC mRNA Expression Before and After Inoculation of $P$. aeruginosa in Two Groups of Rats

\begin{tabular}{lccc}
\hline Time point $(\mathrm{h})$ & $\begin{array}{l}\text { Young group } \\
\text { (CINC/GAPDH, mean } \pm \text { SD) }\end{array}$ & $\begin{array}{l}\text { Aged group } \\
\text { (CINC/GAPDH, mean } \pm \text { SD) }\end{array}$ & $t^{\mathrm{a}}$ \\
\hline 0 & $0.52 \pm 0.41$ & $0.13 \pm 0.05$ & 1.194 \\
2 & $1.25 \pm 0.34$ & $0.26 \pm 0.14$ & 5.393 \\
6 & $2.52 \pm 0.55$ & $0.45 \pm 0.25$ & 6.831 \\
9 & $2.05 \pm 0.58$ & $0.84 \pm 0.58$ & 2.939 \\
12 & $1.88 \pm 0.16$ & $1.55 \pm 0.76$ & 0.002 \\
24 & $0.94 \pm 0.12$ & $1.01 \pm 1.14$ & 0.720 \\
\hline
\end{tabular}

Data presented as mean $\pm \mathrm{SD}$

${ }^{a}$ Non-parametric test

\section{DISCUSSION}

Chemokines are a class of small, secreted proteins that attract white blood cells [9-14]. Many studies have shown that chemokines and their receptors play an important role in pulmonary infectious diseases [15-20]. Many recent studies have analyzed the expression of chemotactic factors in the lungs during infection, but there have been few studies performed in aged subjects. Gomez et al. [21] inoculated lipopolysaccharide (from $P$. aeruginosa) into the lungs of $\mathrm{BALB} / \mathrm{c}$ mice and observed that the transcription levels of MIP-2 and KC in elderly mice were markedly higher than in young mice. In addition, PMN infiltration was greater in the elderly group. This indicated that severe systemic inflammatory responses and exacerbated lung inflammation occurred in elderly subjects and might be a mechanism for the high mortality of elderly rats. Another study investigated the difference of immune functions in young and old mice by inoculation of sub-lethal doses of influenza virus into the lungs of mice, and found that the older group had a higher mortality, slower recovery, increased weight loss, and a delay in infiltrating pulmonary local neutrophils and dendritic cells, corresponding to reduced lung chemokine expression [22].
A previous study indicated that $P$. aeruginosa is the most common hospital-acquired pneumonia pathogen, especially in intensive care units, and causes pneumonia in patients with nosocomial pathogens [23, 24], especially in the elderly, and those that are immunocompromised or with underlying diseases. $P$. aeruginosa is a representative pathogen for aging pneumonia. In addition, PMN and monocytes/giant macrophages play an important role in $P$. aeruginosa-induced lung infection in vitro and in vivo. MCP-1 also has a specific role in monocytes/macrophages recruitment, so we chose to monitor the dynamic changes of these two cell types and the corresponding changes in lung chemokines during infection.

In 2001, a neutropenia rat model of $P$. aeruginosa pneumonia was developed [5]. We followed this modeling approach and determined that tracheal inoculation could establish a $P$. aeruginosa-induced pneumonia model in rats. Relative to the young rat group, elderly rats had a reduced bacterial clearance capacity. The elderly rats demonstrated more severe symptoms with higher mortality, suggesting the aged group had reduced immune defense. In addition, lung edema and hemorrhage were more common in the elderly rats, but with less severe inflammatory responses. Before and after $P$. aeruginosa infection,

Table 8. Dynamic Changes of Lung Tissue MCP-1 mRNA Expression Before and After Inoculation of P. aeruginosa in Two Groups of Rats

\begin{tabular}{lccc}
\hline Time point $(\mathrm{h})$ & Young group (MCP-1/GAPDH, mean $\pm \mathrm{SD}$ ) & Aged group (MCP-1/GAPDH, mean \pm SD) & $t^{\mathrm{a}}$ \\
\hline 0 & $0.56 \pm 0.18$ & $0.28 \pm 0.10$ & 2.705 \\
2 & $0.84 \pm 0.11$ & $0.59 \pm 0.05$ & 3.722 \\
6 & $1.28 \pm 0.09$ & $0.83 \pm 0.06$ & 7.308 \\
9 & $2.22 \pm 0.32$ & $1.26 \pm 0.20$ & 0.014 \\
12 & $1.74 \pm 0.13$ & $1.87 \pm 0.56$ & 0.001 \\
24 & $1.42 \pm 0.02$ & $2.28 \pm 1.12$ & 0.012 \\
\hline
\end{tabular}

Data presented as mean $\pm \mathrm{SD}$

${ }^{a}$ Non-parametric test 
numbers of PMNs and monocytes/macrophages in the lung of aged rats were lower than in young rats. After $P$. aeruginosa infection in aged rats, the infiltration of inflammatory cells, in particular PMNs, was delayed, suggesting local cellular defense responses were reduced. This was consistent with a previous study [25] that demonstrated the most vulnerable patients to $P$. aeruginosa in hospital were those whose PMNs were reduced or whom were under machine ventilation. Their fatality rates could exceed $30 \%$. Differences in pathology between our study and that of Gomez might be related to P. aeruginosa dose, animal selection, research methodology and different time points examined. Our study proposed to analyze acute inflammatory reactions induced by $P$. aeruginosa, and the selection of time points up to $24 \mathrm{~h}$ were based on a previous study [5]. At different time points, the infiltration mechanisms of PMNs and mononuclear/macrophage cells may be different. PMN and monocyte/macrophage infiltration in the lungs of rats was time-dependent. The transcription levels of CINC and MCP-1 genes (rCINC young group $=0.622, P=0.188$; rCINC aged group $=0.970, P=0.001 ;$ rMCP-1 young group $=0.757, P=0.081$; rMCP-1 aged group $=0.997$, $P<0.001)$ were consistent with a previous study [23] that demonstrated CINC and MCP-1 gene expression was reduced in the aged rats group. Thus, aging may cause reduced CINC and MCP-1 gene expression levels, which would weaken the speed and extent of infiltration of PMNs and monocytes/macrophages into lung tissues and affect their defense functions. The poor prognosis and mechanisms of clinical aging pneumonia require further study.

The current study showed some differences compared with a study on the impact of aging on MCP-1 expression by Lin et al. [26], who used 27-month-old female Wistar rats and fibrin to induce acute lung injury. Their study demonstrated that aging contributed to fibrin deposition and enhanced the expression of MCP-1 in lung tissue, which may explain why elderly individuals are more susceptible to inflammatory stimuli. Differences in study findings are probably due to experimental animal selection and the method of establishing the disease model.

P. aeruginos a pneumonia is a common cause of death in the elderly. Effective host defense responses remove pathogenic microorganisms in the host lung tissue. This requires the infiltration of PMNs and monocytes/macrophages to the lung $[26,27]$ attracted by the presence of secreted chemokines.

This research has several limitations. Firstly, we did not conduct a dose gradient experiment. Instead, we just used the common dose used at home and abroad to induce the model of pulmonary infection in young rats to investigate the feasibility in inducing aged rats model. Therefore, the deficiency in this experiment is not to compare between different modeling dose in order to provide a better choice.

Secondly, considering the important role of PMN and macrophage in $P$. aeruginosa pneumonia, we chose to monitor the dynamic changes of these two kinds of cells and the corresponding chemokines (CINC, MCP-1) in pulmonary. However, huge inflammatory cells and chemokines participate in clinical pulmonary inflammation and the concerned regulation mechanism is rather complex. Thus, the advanced mechanism should be studied further.

Thirdly, we studied the expression levels of CINCmRNA and MCP-1mRNA, but the analysis of its protein level was not carried out in our study as to whether the reduction of gene transcription levels in early infection affects protein expression and function. This can be studied in our further research.

Fourthly, the experiments only simulated and investigated the mechanism of acute $P$. aeruginosa pneumonia. So whether we will have the same conclusion concerning chronic $P$. aeruginosa pneumonia still needs to be studied.

In summary, this study demonstrated that aging can reduce the expression of CINC and MCP-1 mRNA in lung tissues, and thus can reduce the infiltration of PMNs and monocytes/macrophages induced by CINC and MCP-1, which may lead to increased risk of pneumonia in the elderly. The molecular and regulatory mechanisms involved require further study.

Conflicts of interest. The authors declared that they have no conflicts of interest to this work

Open Access This article is distributed under the terms of the Creative Commons Attribution License which permits any use, distribution, and reproduction in any medium, provided the original author(s) and the source are credited.

\section{REFERENCES}

1. Louise, E.D., and J.B. Peter. 2006. Chemokine receptors as therapeutic targets in chronic obstructive pulmonary disease. Trends in Pharmacological Sciences 27(10): 546-553.

2. Bonecchi, R., E. Galliera, E.M. Borroni, et al. 2009. Chemokines and chemokine receptors: An overview. Frontiers in Bioscience 14(1): 540-551.

3. Albert, Z., Y. Osamu, and N. Hisayuki. 2006. The chemokine and chemokine receptor superfamilies and their molecular evolution. Genome Biology 7(12): 243.

4. Huang, T.S., F.C. Hu, C.W. Fan, C.H. Lee, S.C. Jwo, and H.Y. Chen. 2010. A simple novel model to predict hospital mortality, surgical site 
infection, and pneumonia in elderly patients undergoing operation. Digestive Surgery 27: 224-231.

5. Li, Z., J. Qu, and L. He. 2001. Establishing a model of neutropenia rat with Pseudomonas aeruginosa pneumonia and a study on its inflammatory reaction. Chinese Journal of Tuberculosis and Respiratory Diseases 24: 674-678 [Article in Chinese].

6. Huang, L., and Z.-L. Liu. 2000. The dynamic change of IL-8 in pulmonary tissue local and serum with Pseudomonas aeruginosa lung infection. Academic Journal of Second Military Medical University 21: 450-425.

7. Pearson, J.P., M. Feldman, B.H. Iglewski, and A. Prince. 2000. Pseudomonas aeruginosa cell-to-cell signaling is required for virulence in a model of acute pulmonary infection. Infection and Immunity 68: 4331-4334.

8. Song, Z.J., H.K. Johansen, V. Faber, and N. Høiby. 1997. Ginseng treatment enhances bacterial clearance and decreases lung pathology in athymic rats with chronic P-aeruginosa pneumonia. APMIS 105: 438-444.

9. Song, Z., A. Kharazmi, H. Wu, V. Faber, C. Moser, H.K. Johansen, and N. Høiby. 1998. Effects of ginseng treatment on neutrophil chemiluminescence and IgG subsets in chronic Pseudomonas aeruginosa pneumonia in rats. Clinical Vaccine Immunology 5: 882-887.

10. Wang, J., Z. Li, M. Zuo, et al. 2005. A contrast study of different automatic hematology analyzers under different modes of determination in white blood cell classification of rats. Laboratory Medicine 20: 201-203.

11. Donnelly, L.E., and P.J. Barnes. 2006. Chemokine receptors as therapeutic targets in chronic obstructive pulmonary disease. Trends in Pharmacological Sciences 27: 546-553.

12. Borroni, E.M., A. Mantovani, M. Locati, and R. Bonecchi. 2010. Chemokine receptors intracellular trafficking. Pharmacology \& Therapeutics 127: 1-8.

13. Deshmane, S.L., S. Kremlev, S. Amini, and B.E. Sawaya. 2009. Monocyte chemoattractant protein-1 (MCP-1): An overview. Journal of Interferon Cytokine Research 29: 313-326.

14. Sharma, M. 2010. Chemokines and their receptors: orchestrating a fine balance between health and disease. Critical Review in Biotechnology 30: $1-22$.

15. Bonecchi, R., E. Galliera, E.M. Borroni, M.M. Corsi, M. Locati, and A. Mantovani. 2009. Chemokines and chemokine receptors: An overview. Frontiers in Bioscience 14: 540-551.

16. Gong, D., K. Farley, M. White, K.L. Hartshorn, C. Benarafa, and E. Remold-O'Donnell. 2011. Critical role of serpinB1 in regulating inflammatory responses in pulmonary influenza infection. Journal of Infectious Diseases 204: 592-600.
17. Tanaka, A., M. Seki, S. Yamahira, H. Noguchi, K. Kosai, M. Toba, Y. Morinaga, T. Miyazaki, K. Izumikawa, H. Kakeya, Y. Yamamoto, K. Yanagihara, T. Tashiro, N. Kohda, and S. Kohno. 2011. Lactobacillus pentosus strain b240 suppresses pneumonia induced by Streptococcus pneumoniae in mice. Letters in Applies Microbiology 53: $35-43$.

18. Qin, S., J.F. Alcorn, J.K. Craigo, C. Tjoeng, P.M. Tarwater, J.K. Kolls, and T.A. Reinhart. 2011. Epigallocatechin-3-gallate reduces airway inflammation in mice through binding to proinflammatory chemokines and inhibiting inflammatory cell recruitment. Journal of Immunology 186: 3693-700.

19. Lindell, D.M., T.J. Standiford, P. Mancuso, Z.J. Leshen, and G.B. Huffnagle. 2001. Macrophage inflammatory protein1 alpha/CCL3 is required for clearance of an acute Klebsiella pneumoniae pulmonary infection. Infection and Immunity 69: 6364-9.

20. Parker, D., and A. Prince. 2011. Innate immunity in the respiratory epithelium. American Journal of Respiratory Cell and Molecular Biology 45: 189-201.

21. Gomez, C.R., S. Hirano, B.T. Cutro, S. Birjandi, H. Baila, V. Nomellini, and E.J. Kovacs. 2007. Advanced age exacerbates the pulmonary inflammatory response after lipopolysaccharide exposure. Critical Care Medicine 35: 246-51.

22. Toapanta, F.R., and T.M. Ross. 2009. Impaired immune responses in the lungs of aged mice following influenza infection. Respiratory Research 10: 112.

23. Fei, M., and D.X. Wang. 2006. Advanced progress on Pseudomonas aeruginosa pneumonia. International Journal of Respiration 26: 250 252 [In Chinese].

24. Yin, P., and W.M. Jin. 2008. Changes in cell-mediated immune function among older inpatients with Pseudomonas aeruginosa pneumonia. Chinese Journal of Nosocomiology 18: 467-469 [In Chinese].

25. Giamarellou, H. 2000. Therapeutic guidelines for Pseudomonas aeruginosa infections. International Journal of Antimicrobial Agents 16: 103-106.

26. Lin, S.P., X.F. Sun, X.M. Chen, S.Z. Shi, C.S. Xi, Q. Hong, and L.V. Yang. 2006. The effect of aging on fibrin deposition up-regulating the expression of monocyte chemoattractant protein 1 in lipopolysaccharide-induced acute lung injury. Chinese Journal of Geriatrics. 25: 606-609 [In Chinese].

27. Toews, G.B., G.N. Gross, and A.K. Pierce. 1979. The relationship of Inoculum size to lung bacterial clearance and phagocytic cell response in mice. American Review of Respiratory Diseases 120: 559-566. 